\title{
Relationship between hair cortisol concentrations and depressive symptoms in patients with coronary artery disease
}

This article was published in the following Dove Press journal:

Neuropsychiatric Disease and Treatment

24 June 2010

Number of times this article has been viewed

\author{
Yekta Dowlati ${ }^{1,3}$ \\ Nathan Herrmann ${ }^{2,3}$ \\ Walter Swardfager ${ }^{1,3}$ \\ Steven Thomson ${ }^{4}$ \\ Paul I $\mathrm{Oh}^{3,5}$ \\ Stan Van Uum ${ }^{4}$ \\ Gideon Koren ${ }^{1,4}$ \\ Krista L Lanctôt ${ }^{1,2,3,5}$ \\ 'Departments of Pharmacology and \\ Toxicology and ${ }^{2}$ Psychiatry, University \\ of Toronto; ${ }^{3}$ Sunnybrook Health \\ Sciences Centre, ${ }^{4}$ Department of \\ Medicine, University of Western \\ Ontario; ${ }^{5}$ Toronto Rehabilitation \\ Institute, Ontario, Canada
}

Objective: Concentrations of cortisol in hair, a novel marker of longer-term cortisol status, were compared in depressed versus nondepressed patients with coronary artery disease (CAD).

Methods: $20 \mathrm{mg}$ hair samples of $3 \mathrm{~cm}$ length were collected from 121 patients attending a cardiac rehabilitation program, 34 of whom suffered from depressive symptoms.

Results: Controlling for age, gender, coronary artery bypass grafting, history of depression, and time since most recent acute coronary syndrome, cortisol concentrations $(P=0.162)$ did not predict severity of depression. Younger age $(P=0.003)$ was a significant predictor of depressive symptoms. Perceived stress was not associated with long-term cortisol concentrations $(P=0.161)$.

Conclusions: Cortisol concentrations in hair do not predict depressive symptoms in CAD patients attending cardiac rehabilitation.

Keywords: cortisol, depression, hair, coronary artery disease

\section{Introduction}

The prevalence of depression in the general population ranges from $4.4 \%$ to $20 \%$, but the prevalence in patients with coronary artery disease (CAD) is at least 2-fold higher. ${ }^{1-3}$ About $20 \%$ of patients with CAD suffer from major depression (MD) within 1 year following an acute coronary syndrome (ACS) while another $27 \%$ do not meet diagnostic criteria but show depressive symptoms or suffer from minor depression. ${ }^{4-6}$ In those with CAD, depressive comorbidity is associated with an increased risk of mortality and medical morbidity independent of traditional cardiac risk factors, ${ }^{7-10}$ and can significantly affect recovery after a major ACS. ${ }^{11,12}$ Depression also has a negative impact on rehabilitation outcomes such as medication adherence, ${ }^{13}$ cardiopulmonary fitness, ${ }^{14,15}$ psychosocial rehabilitation, ${ }^{16,17}$ and overall quality of life. ${ }^{9}$ Moreover, clinical studies of depression in CAD patients show poor response rates and residual symptoms following treatment with selective serotonin reuptake inhibitors. ${ }^{18,19}$ Understanding the etiology of depression associated with CAD is therefore of clinical importance.

It has been shown that depressive symptoms and psychological stress tend to decline over the course of cardiac rehabilitation in concert with an increase in quality of life, while cardiac risk factor profiles improve concurrently, reducing mortality and morbidity. ${ }^{20-25}$ However, symptoms may persist in many patients with depression. Studies have shown that $95 \%$ of patients with untreated MD following myocardial infarction (MI) will remain depressed at six months, and up to $70 \%$ will remain depressed at 1 year. ${ }^{2,26}$ The reasons why only some patients remain chronically depressed are not understood.
Correspondence: Krista L Lanctôt Sunnybrook Health Sciences Centre, 2075 Bayview Avenue, Room FG05, Toronto, ON, M4N 3M5, Canada Tel + I 4I64806I00 ext 224I $\mathrm{Fax}+\mathrm{I} 4164806022$

Email krista.lanctot@sunnybrook.ca submit your manuscript | www.dovepress.com 
High concentrations of cortisol, the main steroid hormone associated with the stress response system, have been detected in patients with depression. ${ }^{27-30}$ Ongoing elevations have also been associated with risk factors for CAD, including high blood pressure, elevated heart rate, higher waist-to-hip ratio, insulin resistance, diabetes, elevated total and LDL cholesterol, and decreased HDL cholesterol. ${ }^{31-33}$ The relationship between cortisol and depression may be particularly important in CAD patients, because elevated concentrations of cortisol due to hypothalamic-pituitary-adrenal (HPA) axis hyperactivity may be associated with an increased risk of mortality and medical comorbidity. ${ }^{31,34-36}$ Ongoing activation of the HPA axis and high concentrations of cortisol may also be important in the persistence of depressive symptoms.

Typically, concentrations of cortisol in the bloodstream are subject to diurnal variation. Normally, cortisol concentrations peak in the morning and subside in the evening, with the lowest concentrations occurring around midnight. ${ }^{37,38}$ However, in depressed patients this pattern is disrupted and, instead, cortisol peaks earlier in the morning and decreases less in the evening, resulting in increased systemic cortisol exposure. ${ }^{39}$

Previously, cortisol measurements in saliva, plasma, and urine, have shown short-term changes in the hormone over a period of up to 24 hours. ${ }^{40,41}$ These methods are validated measures of acute stress, but they are subject to the normal diurnal variation in cortisol secretion, and are easily affected by temporary or transient disturbances in psychosocial stress on the day of measurement. Biopsychosocial stressors associated with CAD, however, are likely to be chronic. Therefore, in order to better understand the association between cortisol levels and depression in CAD, long-term measurement of cortisol may be more appropriate, necessitating multiple blood, saliva, or urine samples. ${ }^{42}$

Recently, a new method has been developed to measure cortisol in hair samples. Because hair grows at a rate of about $1 \mathrm{~cm}$ per month, hair cortisol concentrations may provide a long-term measure of cortisol, thereby obviating the need for frequent sampling. ${ }^{43}$ This method has been validated and shown to be significantly correlated with 24-hour urinary cortisol, therefore having an ability to be used as a biomarker for long-term measurements. ${ }^{43}$ This method has also been validated in a postpartum sample where hair cortisol was shown to capture the known increased production of cortisol during the third trimester. ${ }^{44}$ The relationship between stress and elevated levels of cortisol in hair has also been shown. In a study by Van Uum et al in patients with chronic pain, hair cortisol was higher in patients with major chronic pain. ${ }^{45}$ Moreover, in a recent study, hair cortisol measurements were done in patients with Cushing's syndrome, and results indicated that hair cortisol levels were significantly higher than that in healthy controls. ${ }^{46}$

The objective of this study was to investigate the relationship between depressive symptoms and long-term hair concentrations of cortisol in CAD patients.

\section{Methods}

\section{Subjects and setting}

This was a cross-sectional study of sequentially recruited subjects attending the Toronto Rehabilitation Institute Cardiac Rehabilitation and Secondary Prevention Program (TRI-Cardiac). All experiments on human subjects were conducted in accordance with the Declaration of Helsinki. ${ }^{47}$ All participants gave written informed consent before inclusion in the study. This study was approved by the local Research Ethics Boards. Demographic details and medical history were obtained by electronic chart review.

CAD subjects were identified based on a history of MI, coronary angiographic evidence of $\geq 50 \%$ blockage in at least one major coronary artery, or prior revascularization, such as percutaneous coronary intervention (PCI) procedures or coronary artery bypass graft (CABG) surgery at the time of enrolment at the TRI-Cardiac. All CAD patients had entered cardiac rehabilitation a minimum of 6-8 weeks post-CABG ( 6 weeks for uncomplicated CABG), a minimum of 6 weeks post-MI, or a minimum of 3 weeks post-PCI. TRI-Cardiac involves a 1-year exercise program consisting of both aerobic and resistance training in a group setting with supervision by exercise and medical specialists. Patients were excluded if they had a significant acute medical illness such as cancer, Parkinson's disease, or multiple sclerosis, if a premorbid psychiatric diagnosis of schizophrenia or bipolar disorder was present, or if they had significant cognitive impairment.

Patients were recruited either at entry into the rehabilitation program or at the time of completion of the program after one year to coincide with aerobic testing.

\section{Diagnosis of depression}

Depression was diagnosed based on patient history and on a structured clinical interview for depression according to the Diagnostic and Statistical Manual of Mental Disorders version IV (DSM-IV-TR) performed at the time of cortisol sampling. ${ }^{48,49}$ Criteria for diagnosing a major depression included either depressed mood or anhedonia, in combination with changes in appetite and/or weight, insomnia or hypersomnia, agitation or retardation, fatigue or loss of energy, 
feelings of worthlessness or guilt, diminished ability to think or being indecisive, or current thoughts of own death. Subjects satisfying 5 of 9 criterion symptoms for 2 weeks, including either sadness or anhedonia, were diagnosed as having MD. Subjects were diagnosed with minor depression if they satisfied 3 criteria, 1 of which was sadness or anhedonia. The presence of a personal or family history of depression was also collected from the subjects.

Severity of depressive symptoms was measured using the Center for Epidemiological Studies Depression Scale (CES-D), ${ }^{50}$ a 20-item depression inventory scored from 0 (least depressed) to 60 (most depressed). This scale has been used extensively in CAD populations. ${ }^{15,51}$

\section{Stress measurement}

Long-term subjective stress was measured using the Perceived Stress Scale (PSS), ${ }^{52}$ a 10-item self-report instrument scored from 0 to 40 that gauges psychological stress responses within the past month. The survey items are short and easy to understand, and this scale has been used widely to investigate relationships with cortisol. ${ }^{53}$ Time since most recent ACS was also documented as a source of stress and was controlled for in analyses.

\section{Hair samples}

A $20 \mathrm{mg}$ hair sample, $3 \mathrm{~cm}$ in length (as a measure of average cortisol over the previous 3-month period), was collected by study personnel. All samples were collected from the vertex posterior as close to the scalp as possible using fine-tipped surgical scissors as per our standard protocol. It has previously been demonstrated that cortisol concentrations are not affected by natural hair color nor by dying of the hair. ${ }^{43,45,53}$

\section{Cortisol assays}

Each sample was weighed and minced finely with scissors. Afterwards, $1 \mathrm{~mL}$ of methanol was added, and the suspension was sonicated for 30 minutes and then incubated overnight for 16 hours at $52^{\circ} \mathrm{C}$. After incubation, the methanol was removed from each sample and placed in a glass tube and evaporated in a dry bath under a stream of nitrogen gas. Upon evaporation of methanol, $250 \mu \mathrm{L}$ of phosphate-buffered saline solution at $\mathrm{pH} 8.0$ was added to the sample and vortexed until well mixed. ${ }^{43}$ Cortisol measurement was performed using the salivary enzyme-linked immunosorbent assay cortisol kit (Alpco Diagnostics, New Hampshire, US). The extracts were run on the assay according to the instructions from the manufacturer. ${ }^{43}$ Patients with cortisol concentrations over $1500 \mathrm{ng} / \mathrm{g}$ were excluded because these levels are suggestive of Cushing's syndrome or contamination by cream containing hydrocortisone. ${ }^{54}$

\section{Statistical analysis}

Continuous variables were summarized using independent samples t-tests and reported as means $\pm \mathrm{SD}$, whereas categorical measures were summarized using chi-square tests and report as counts and percentages.

The association between cortisol and depression as a categorical variable was assessed using analysis of covariance (ANCOVA). Given that there were 34 patients in the "depressed" cohort, only 4 variables could be used in the model, ie, history of depression, marital status, and age in addition to cortisol. This selection was based on strength of association with depression (see Table 1), and minimal multicollinearity.

Linear regression was performed between depressive symptoms as a continuous variable, using CES-D scores, and cortisol, with covariates of interest such as age, gender, marital status, and time since most recent ACS. Linear regression was also used to assess the association between stress, as measured by PSS scores as a continuous variable, and concentrations of cortisol, with covariates of interest such as age, gender, marital status, and time since most recent ACS in CAD patients.

Since both the presence of depression and depression severity were assessed as primary outcomes, the Bonferroni correction was used in all analyses. Significance was set at $P<0.025(0.05 / 2)$.

Hair cortisol concentrations were not normally distributed among patients and were transformed to a logarithmic scale for all analyses.

\section{Results Subjects}

Of 246 patients attending cardiac rehabilitation who were approached for participation, $141 \mathrm{CAD}$ patients were recruited. Fourteen patients were excluded because they had insufficient hair for analysis. One hundred and twenty-seven patients provided hair samples that were analyzed for cortisol concentration. Of these patients, 6 were excluded because their hair cortisol concentration was higher than $1500 \mathrm{ng} / \mathrm{g} .{ }^{54}$ Therefore, $121 \mathrm{CAD}$ patients were included in this study. Of these, 34 were depressed and 87 were not depressed (see Figure 1). The sociodemographic characteristics of these patients are summarized in the Table 1.

As expected, mean CES-D scores were significantly higher in depressed patients compared with nondepressed patients $(\mathrm{F}=27.9$, degrees of freedom $[\mathrm{DF}]=118, P<0.0005)$, as were 
Table I Patient characteristics $(n=121)$

\begin{tabular}{|c|c|c|c|}
\hline & $\begin{array}{l}\text { Nondepressed } \\
(n=87)\end{array}$ & $\begin{array}{l}\text { Depressed } \\
(n=34)\end{array}$ & $\begin{array}{l}\text { Significance } \\
P \text { value }\end{array}$ \\
\hline \multicolumn{4}{|l|}{ Sociodemographic } \\
\hline $\begin{array}{l}\text { Age in years } \\
(\text { mean } \pm \text { SD) }\end{array}$ & $65.7 \pm 11.1$ & $61.6 \pm 12.9$ & 0.09 \\
\hline $\begin{array}{l}\text { Employment } \\
\text { (\% employed) }\end{array}$ & 51.7 & 47.1 & 0.64 \\
\hline $\begin{array}{l}\text { Marital status } \\
\text { (\% married) }\end{array}$ & 81.6 & 58.8 & $0.01 *$ \\
\hline Sex (\% male $)$ & 80.5 & 64.7 & 0.07 \\
\hline $\begin{array}{l}\text { Smoking status } \\
\text { (\% current smoker) }\end{array}$ & 3.4 & 0 & 0.33 \\
\hline $\begin{array}{l}\text { Weeks since cardiac } \\
\text { event (mean } \pm \text { SD) }\end{array}$ & $34.4 \pm 36.4$ & $38.6 \pm 33.3$ & 0.56 \\
\hline \multicolumn{4}{|l|}{ Anthropometric } \\
\hline $\begin{array}{l}\text { BMI }\left(\mathrm{kg} / \mathrm{m}^{2}\right) \\
(\text { mean } \pm \mathrm{SD})\end{array}$ & $27.5 \pm 4.9$ & $28.5 \pm 6.5$ & 0.32 \\
\hline $\begin{array}{l}\text { Weight (lb) } \\
\text { (mean } \pm \text { SD) }\end{array}$ & $178.0 \pm 37.5$ & $174.1 \pm 38.9$ & 0.61 \\
\hline \multicolumn{4}{|l|}{ Physiology } \\
\hline $\begin{array}{l}\text { Systolic blood } \\
\text { pressure } \\
\text { (mean } \pm \mathrm{SD})\end{array}$ & $130.8 \pm 17.8$ & $124.1 \pm 17.8$ & 0.07 \\
\hline $\begin{array}{l}\text { Diastolic blood } \\
\text { pressure } \\
(\text { mean } \pm S D)\end{array}$ & $73.6 \pm 10.8$ & $74.3 \pm 9.1$ & 0.74 \\
\hline \multicolumn{4}{|l|}{ Cardiac factors n (\%) } \\
\hline Myocardial Infarction & $39(44.8)$ & I5 (44.I) & 0.94 \\
\hline CABG & $30(34.5)$ & II (32.4) & 0.82 \\
\hline $\mathrm{PCl}$ & $39(44.8)$ & $13(38.2)$ & 0.51 \\
\hline Angina pectoris & $22(25.3)$ & $7(20.6)$ & 0.58 \\
\hline Hypertension & $47(54.0)$ & $16(47.1)$ & 0.49 \\
\hline \multicolumn{4}{|c|}{ Medical comorbidities n (\%) } \\
\hline Diabetes & $22(25.3)$ & $6(17.6)$ & 0.37 \\
\hline Renal disease & $2(2.3)$ & I (2.9) & 1.00 \\
\hline COPD & $4(4.6)$ & $2(5.9)$ & 0.77 \\
\hline Asthma & $3(3.4)$ & $0(0.0)$ & 0.27 \\
\hline $\begin{array}{l}\text { History of } \\
\text { depression }\end{array}$ & $7(9.6)$ & $10(33.3)$ & $0.005^{*}$ \\
\hline \multicolumn{4}{|c|}{ Concomitant medication $\mathbf{n}(\%)$} \\
\hline$\beta$-blockers & $60(69.0)$ & $22(64.7)$ & 0.65 \\
\hline Statins & 81 (93.I) & 31 (9I.2) & $0.7 \mathrm{I}$ \\
\hline Nitroglycerin & $45(5 \mid .7)$ & $17(50.0)$ & 0.86 \\
\hline $\begin{array}{l}\mathrm{Ca}^{2+} \text { channel } \\
\text { blockers }\end{array}$ & $19(21.8)$ & II (32.4) & 0.23 \\
\hline Antihypertensives & $5 \mathrm{I}(58.6)$ & $20(58.8)$ & 0.98 \\
\hline Platelet inhibitors & $80(92.0)$ & $32(94.1)$ & 1.00 \\
\hline \multicolumn{4}{|c|}{ Psychotropic medications n (\%) } \\
\hline Anxiolytics & $5(5.7)$ & $8(23.5)$ & $0.008 *$ \\
\hline Antidepressants & $3(3.4)$ & $3(8.8)$ & 0.35 \\
\hline \multicolumn{4}{|l|}{ Scales } \\
\hline $\begin{array}{l}\text { CES-D score } \\
(\text { mean } \pm S D)\end{array}$ & $6.5 \pm 4.8$ & $24.5 \pm 10.1$ & $<0.005^{*}$ \\
\hline $\begin{array}{l}\text { PSS score } \\
\text { (mean } \pm \text { SD) }\end{array}$ & $10.6 \pm 6.7$ & $21.0 \pm 5.5$ & $<0.005^{*}$ \\
\hline
\end{tabular}

*Statistically significant.

Abbreviations: BMI, body mass index; CABG, coronary artery bypass graft; CES-D, Center for Epidemiological Studies Depression; COPD, chronic obstructive pulmonary disease; $\mathrm{PCI}$, percutaneous coronary intervention; PSS, Perceived Stress Scale; SD, standard deviation. mean PSS scores $(\mathrm{F}=1.81, \mathrm{df}=118, P<0.0005)$. In addition, there were trends for depressed patients to be slightly younger, unmarried, and female, and significantly greater proportions of depressed patients were taking anxiolytics (see Table 1).

\section{Assay results}

All collected hair samples were of adequate weight for analysis of cortisol. Hair color and hair dye data were collected from 83 of 121 samples; among these 34 were grey, 14 white, 14 black, 18 brown, and 3 blonde hair samples. The log-transformed mean hair cortisol concentration among the samples that had applied hair dye $(\mathrm{n}=5)$ and the ones who have not been treated with dye $(\mathrm{n}=78)$ was not significantly different $(4.77 \pm 0.70$ versus $4.95 \pm 0.57, \mathrm{~F}=0.49$, $\mathrm{df}=81$, $P=0.49)$. The log-transformed mean cortisol concentration for nondepressed patients $(\mathrm{n}=87)$ was $5.04 \pm 0.59$, and

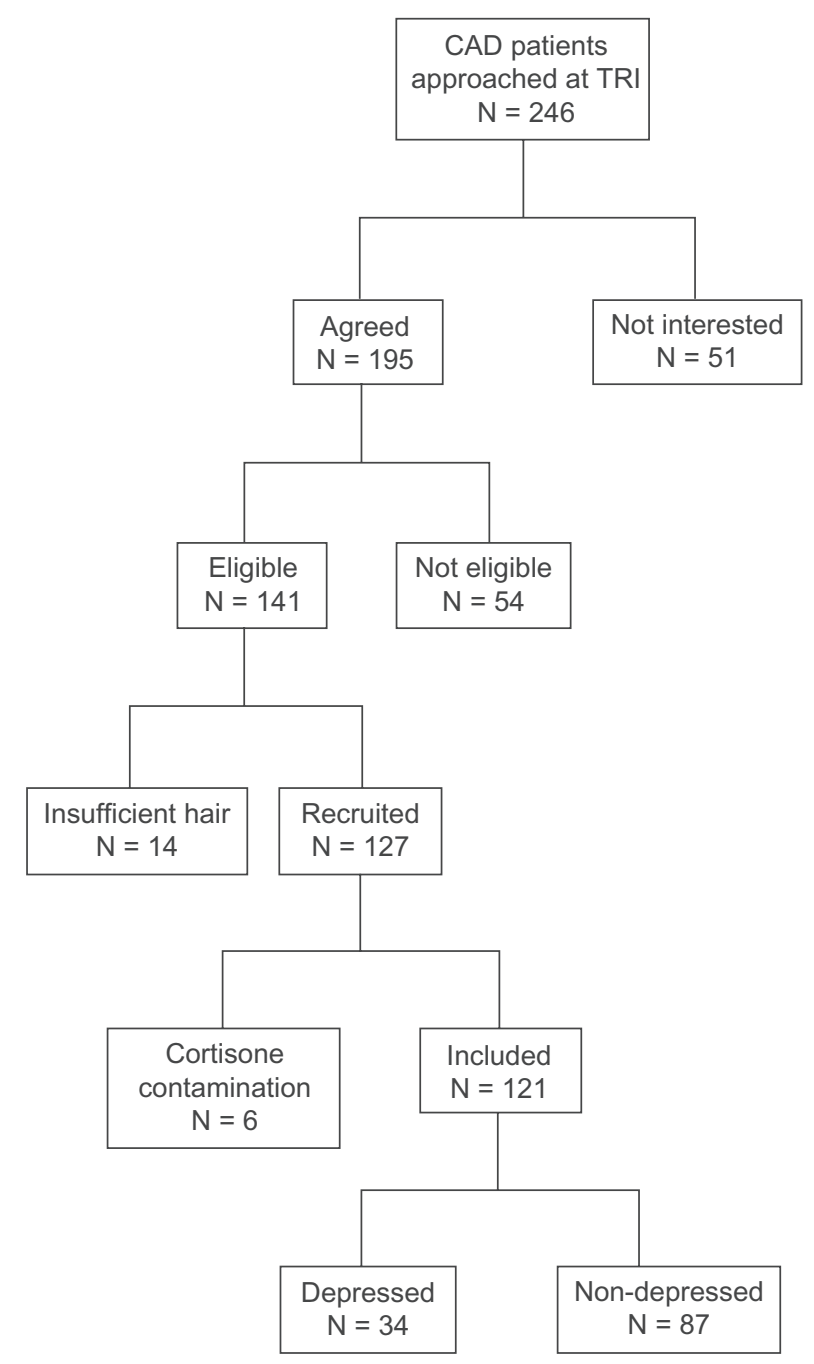

Figure I Flow chart of recruitment process.

Abbreviations: CAD, coronary artery disease; TRI, Toronto Rehabilitation Institute Cardiac Rehabilitation and Secondary Prevention Program (TRI-Cardiac). 
for depressed patients $(n=34)$ was $4.96 \pm 0.58$, and the values were not significantly different $(\mathrm{F}=0.393, \mathrm{df}=119$, $P=0.53$ ). Mean cortisol concentrations were not different between patients assessed at baseline or at completion of rehabilitation $(P=0.109, \mathrm{~F}=0.260, \mathrm{df}=119)$.

\section{Hair cortisol and depression}

There was no significant difference in the concentration of hair cortisol between depressed and nondepressed patients $(P=0.825)$ in an ANCOVA controlling for age, marital status, and history of depression. Marital status $(P=0.021)$ and history of depression $(P=0.008)$ remained in the final model as the only variables significantly predictive of depression $\left(\chi^{2}=13.26, \mathrm{R}^{2}=0.172, P=0.001\right)$. Gender, time since most recent $\mathrm{ACS}$, and $\mathrm{CABG}$ were excluded from the ANCOVA based on a lower strength of association (see Table 1).

In a linear regression model predicting severity of depressive symptoms as measured by CES-D scores, including concentrations of cortisol, age, gender, marital status, and time since most recent ACS, cortisol was not associated with CES-D scores (beta $=-0.148, P=0.162)$. Gender $($ beta $=0.042$, $P=0.678)$, marital status (beta $=0.021, P=0.837$ ), CABG (beta $=-0.035, P=0.747$ ), and time since most recent ACS (beta $=0.019, P=0.846$ ) were also removed from the model. In the final model, younger age (beta $=-0.274, P=0.003$ ) was significantly associated with CES-D scores $\left(\mathrm{R}^{2}=0.088\right.$, $P=0.004, \mathrm{~F}=5.86, \mathrm{df}=101$ ), and personal history of depression trended towards significance (beta $=-183, P=0.059$ ).

In a linear regression model predicting perceived stress, including cortisol concentration, age, gender, marital status, CABG, history of depression, and time since most recent ACS, cortisol was not associated with PSS scores (beta $=-0.149, P=0.161)$. Gender $($ beta $=0.124, P=0.226)$, marital status (beta $=-0.080, P=0.438)$, history of depression (beta $=-0.006, P=0.957$ ), time since most recent ACS (beta $=-0.004, P=0.965)$, and CABG (beta $=-0.057$, $P=0.597$ ) were also not significantly associated with PSS scores. In the final model, only younger age (beta $=-0.245$, $P=0.013)$ was associated with PSS scores $\left(\mathrm{R}^{2}=0.051\right.$, $P=0.013, \mathrm{~F}=6.41, \mathrm{df}=101)$.

There were no differences in average concentration of cortisol between married versus single participants $(P=0.7, \mathrm{~F}=0.18, \mathrm{df}=119)$, males versus females $(P=0.9$, $\mathrm{F}=1.1, \mathrm{df}=119)$, those with major or minor depression $(P=0.6, \mathrm{~F}=0.88, \mathrm{df}=31)$, those recruited at entry or at their final visit $(P=0.094, \mathrm{~F}=2.850, \mathrm{df}=120)$, those on or off anxiolytic medications $(P=0.3, \mathrm{~F}=0.24, \mathrm{df}=119)$, or those with a history of depression $(P=0.17, \mathrm{~F}=2.81, \mathrm{df}=101)$.
There were differences in average concentration of cortisol between those who had CABG and those who did not $(P=0.002, \mathrm{~F}=1.04, \mathrm{df}=119)$. This suggests that a stressful intervention, such as a $\mathrm{CABG}$, has significant effects on cortisol levels. Another putative source of stress, ie, angina, did not have significant effects on total cortisol levels $(P=0.642, \mathrm{~F}=0.075, \mathrm{df}=119)$.

\section{Discussion}

The present study found no association between long-term concentrations of cortisol and depression or perceived stress in CAD patients. Single marital status and a positive history of depression were found to be significant predictors of the presence of depression, as has been found before. ${ }^{55}$ Similarly, cortisol did not predict severity of depressive symptoms or perceived stress, and only younger age ${ }^{56}$ was associated with both of these. This study utilized a novel method, cortisol deposition in hair, to measure longer-term HPA axis activity. Examination of long-term cortisol concentration in hair is an important complement to other methods which determine short-term changes in cortisol concentrations.

A positive association has previously been documented between depression and acute cortisol measurements. ${ }^{57,58}$ Otte et al found an association between 24-hour urinary cortisol and depression in outpatients with coronary heart disease. ${ }^{57}$ Similarly, Bhattacharyya et al reported an impaired diurnal pattern of cortisol secretion with flatter cortisol rhythms during the day in CAD patients with depression. ${ }^{58}$ Thus, the results from this study using longer-term measurement contrast with those of shorter-term cortisol measurement in CAD. However, in a recent study by Whooley et al 24-hour urinary cortisol had no significant role in explaining the association between depressive symptoms and adverse cardiovascular events. ${ }^{59}$

Our findings may reflect widespread cortisol concentration elevations in our population, as has been seen before. ${ }^{60}$ Mean concentrations of cortisol in both our groups of patients appear higher compared with concentrations of hair cortisol measured in healthy young subjects. ${ }^{54}$ The higher average cortisol concentrations in both depressed and nondepressed CAD patients may reflect the ubiquitous presence of cardiovascular risk factors such as hypertension, diabetes, and obesity, which may be inherently associated with HPA axis dysregulation. ${ }^{32,61,62}$ In addition, all of our CAD patients suffered from a significant event that may have led to ongoing psychosocial stress, another factor that can increase cortisol concentrations in hair. ${ }^{45,53}$ While having a recent ACS may also be associated with increased cortisol, ${ }^{60}$ time since ACS was not significantly associated with cortisol concentrations, 
or perceived stress, suggesting that these elevations persist. The resulting chronic cortisol changes would then make it impossible to distinguish between depressed and nondepressed patients using this measure.

Several factors should be considered in interpreting these results. Some participants were receiving concomitant psychotropic medications. In general, there was a low rate of antidepressant use among depressed patients in our population, making it unlikely that antidepressant use affected the results. Similarly, hair cortisol concentrations did not differ in those taking or not taking anxiolytics. The sample size of depressed patients was also relatively small, and comprised both those with major and minor depression. However, there were no differences in hair cortisol concentration in those with major versus minor depression. Also, given the complete lack of a trend for differences between depressed and nondepressed groups, power is not a relevant issue here.

We found that those with depressive symptoms had higher mean PSS scores. This, and the fact that those with depressive symptoms had more use of anxiolytics, suggests comorbid anxiety. Anxiety was not directly investigated in this study. Because anxiety and depression commonly co-occur and the presence of anxiety may stimulate the HPA axis, ${ }^{63}$ anxiety might be an important cofactor in this population. State and trait anxiety should be evaluated in conjunction with depression and stress in future studies to better understand this relationship.

It would also be interesting to compare hair cortisol concentrations in this group of patients with healthy agematched controls, and those with MD but no CAD. Long-term cortisol in hair has not been measured in solely depressed subjects or in different types of depression, including melancholic and nonmelancholic. As a result, it is not clear whether the method has the sensitivity to detect changes in HPA axis functioning that would be typical of those found in MD. An additional limitation of this study is that it is unknown how long depressive episodes lasted prior to collection of the hair sample. Finally, medical history was ascertained by chart review, and patients were not specifically questioned about somatic diseases such as thyroid dysfunction, ${ }^{64}$ which could disrupt HPA axis function and lead to altered cortisol levels.

\section{Conclusion}

This study found no association between chronically elevated concentrations of cortisol and depression or stress in CAD patients attending rehabilitation. Known demographic covariates such as marital status, age, and history of depression were significant predictors, and none of these are targets for intervention. Depression is a significant problem in CAD patients and the biologic factors that may mediate this comorbidity remain largely unknown. Further research investigating the relationship between depression and CAD is warranted.

\section{Acknowledgments}

The authors acknowledge Drummond Foundation, Grant 2006RFA-\#6 for their support.

\section{Disclosure}

None of the authors have any conflicts of interest to disclose.

\section{References}

1. Carney RM, Rich MW, Freedland KE, et al. Major depressive disorder predicts cardiac events in patients with coronary artery disease. Psychosom Med. 1988;50(6):627-633.

2. Schleifer SJ, Macari-Hinson MM, Coyle DA, et al. The nature and course of depression following myocardial infarction. Arch Intern Med. 1989;149(8):1785-1789.

3. Bush DE, Ziegelstein RC, Patel UV, et al. Post-myocardial infarction depression. Evid Rep Technol Assess (Summ). 2005;(123):1-8.

4. Lesperance F, Frasure-Smith N. Depression and coronary artery disease: Time to move from observation to trials. CMAJ. 2003;168(5):570-571.

5. Frasure-Smith N, Lesperance F, Talajic M. Depression following myocardial infarction. Impact on 6-month survival. JAMA. 1993;270(15):1819-1825.

6. Frasure-Smith N, Lesperance F, Talajic M. Depression and 18-month prognosis after myocardial infarction. Circulation. 1995;91(4):999-1005.

7. Frasure-Smith N, Lesperance F, Juneau M, et al. Gender, depression, and one-year prognosis after myocardial infarction. Psychosom Med. 1999;61(1):26-37.

8. Lett HS, Blumenthal JA, Babyak MA, et al. Depression as a risk factor for coronary artery disease: Evidence, mechanisms, and treatment. Psychosom Med. 2004;66(3):305-315.

9. Ruo B, Rumsfeld JS, Hlatky MA, et al. Depressive symptoms and health-related quality of life: The Heart and Soul Study. JAMA. 2003;290(2):215-221.

10. Strik JJ, Honig A, Maes M. Depression and myocardial infarction: Relationship between heart and mind. Prog Neuropsychopharmacol Biol Psychiatry. 2001;25(4):879-892.

11. Rozanski A, Blumenthal JA, Davidson KW, et al. The epidemiology, pathophysiology, and management of psychosocial risk factors in cardiac practice: The emerging field of behavioral cardiology. J Am Coll Cardiol. 2005;45(5):637-651.

12. Allison TG, Williams DE, Miller TD, et al. Medical and economic costs of psychologic distress in patients with coronary artery disease. Mayo Clin Proc. 1995;70(8):734-742.

13. Blumenthal JA, Williams RS, Wallace AG, et al. Physiological and psychological variables predict compliance to prescribed exercise therapy in patients recovering from myocardial infarction. Psychosom Med. 1982;44(6):519-527.

14. Lavoie KL, Fleet RP, Lesperance F, et al. Are exercise stress tests appropriate for assessing myocardial ischemia in patients with major depressive disorder? Am Heart J. 2004;148(4):621-627.

15. Swardfager W, Herrmann N, Dowlati Y, et al. Relationship between cardiopulmonary fitness and depressive symptoms in cardiac rehabilitation patients with coronary artery disease. $J$ Rehabil Med. 2008;40(3):213-218. 
16. Stern MJ, Pascale L, Ackerman A. Life adjustment postmyocardial infarction: Determining predictive variables. Arch Intern Med. 1977;137(12):1680-1685.

17. Mayou R, Foster A, Williamson B. Psychosocial adjustment in patients one year after myocardial infarction. J Psychosom Res. 1978;22(5):447-453.

18. Glassman AH, O’Connor CM, Califf RM, et al. Sertraline treatment of major depression in patients with acute MI or unstable angina. JAMA. 2002;288(6):701-709.

19. Lesperance F, Frasure-Smith N, Koszycki D, et al. Effects of citalopram and interpersonal psychotherapy on depression in patients with coronary artery disease: The Canadian Cardiac Randomized Evaluation of Antidepressant and Psychotherapy Efficacy (CREATE) trial. JAMA. 2007;297(4):367-379.

20. Lavie CJ, Milani RV, Cassidy MM, et al. Effects of cardiac rehabilitation and exercise training programs in women with depression. Am J Cardiol. 1999;83(10):1480-1483.

21. Milani RV, Lavie CJ, Cassidy MM. Effects of cardiac rehabilitation and exercise training programs on depression in patients after major coronary events. Am Heart J. 1996;132(4):726-732.

22. Milani RV, Lavie CJ. Prevalence and effects of cardiac rehabilitation on depression in the elderly with coronary heart disease. Am J Cardiol. 1998;81(10):1233-1236.

23. Lavie CJ, Milani RV. Cardiac rehabilitation and depression. Am J Cardiol. 2004;93(8):1080.

24. Lavie CJ, Milani RV. Adverse psychological and coronary risk profiles in young patients with coronary artery disease and benefits of formal cardiac rehabilitation. Arch Intern Med. 2006;166(17): 1878-1883.

25. Blumenthal JA, Sherwood A, Babyak MA, et al. Effects of exercise and stress management training on markers of cardiovascular risk in patients with ischemic heart disease: A randomized controlled trial. JAMA. 2005;293(13):1626-1634.

26. Ladwig KH, Roll G, Breithardt G, et al. Post-infarction depression and incomplete recovery 6 months after acute myocardial infarction. Lancet. 1994;343(8888):20-23.

27. Young EA, Haskett RF, Grunhaus L, et al. Increased evening activation of the hypothalamic-pituitary-adrenal axis in depressed patients. Arch Gen Psychiatry. 1994;51(9):701-707.

28. Deuschle M, Schweiger U, Weber B, et al. Diurnal activity and pulsatility of the hypothalamus-pituitary-adrenal system in male depressed patients and healthy controls. J Clin Endocrinol Metab. 1997;82(1):234-238.

29. Posener JA, DeBattista C, Williams GH, et al. 24-Hour monitoring of cortisol and corticotropin secretion in psychotic and nonpsychotic major depression. Arch Gen Psychiatry. 2000;57(8):755-760.

30. Carroll BJ, Curtis GC, Davies BM, et al. Urinary free cortisol excretion in depression. Psychol Med. 1976;6(1):43-50.

31. Brown ES, Varghese FP, McEwen BS. Association of depression with medical illness: Does cortisol play a role? Biol Psychiatry. 2004;55(1):1-9.

32. Rosmond R, Bjorntorp P. The hypothalamic-pituitary-adrenal axis activity as a predictor of cardiovascular disease, type 2 diabetes and stroke. J Intern Med. 2000;247(2):188-197.

33. Agabiti-Rosei E, Alicandri C, Beschi M, et al. Relationships between plasma catecholamines, renin, age and blood pressure in essential hypertension. Cardiology. 1983;70(6):308-316.

34. McEwen BS. Mood disorders and allostatic load. Biol Psychiatry. 2003;54(3):200-207.

35. Cirimele V, Kintz P, Dumestre V, et al. Identification of ten corticosteroids in human hair by liquid chromatography-ionspray mass spectrometry. Forensic Sci Int. 2000;107(1-3):381-388.

36. Wolkowitz OM, Epel ES, Reus VI. Stress hormone-related psychopathology: Pathophysiological and treatment implications. World J Biol Psychiatry. 2001;2(3):115-143.

37. Wust S, Wolf J, Hellhammer DH, et al. The cortisol awakening responsenormal values and confounds. Noise Health. 2000;2(7):79-88.
38. Clow A, Thorn L, Evans P, et al. The awakening cortisol response: Methodological issues and significance. Stress. 2004;7(1):29-37.

39. Stokes PE. The potential role of excessive cortisol induced by HPA hyperfunction in the pathogenesis of depression. Eur Neuropsychopharmacol. 1995;5 Suppl:77-82.

40. Cook CJ, Mellor DJ, Harris PJ, Ingram JR, Matthews LR. Hands-on and hands-off measurements of stress. In: Moberg GP, Mench JA, editors. The Biology of Animal Stress. New York, NY: CAB International Publishing; 2000.

41. Kirschbaum C, Hellhammer DH. Salivary cortisol in psychoneuroendocrine research: Recent developments and applications. Psychoneuroendocrinology. 1994;19(4):313-333.

42. Aron D, Findling J, Tyrrell J. Glucocorticoids and Adrenal Androgens. 7th ed. New York, NY: Lange Medical Books/McGraw-Hill; 2004.

43. Sauve B, Koren G, Walsh G, et al. Measurement of cortisol in human hair as a biomarker of systemic exposure. Clin Invest Med. 2007;30(5):E183-E191

44. Kirschbaum C, Tietze A, Skoluda N, et al. Hair as a retrospective calendar of cortisol production - increased cortisol incorporation into hair in the third trimester of pregnancy. Psychoneuroendocrinology. 2009;34(1):32-37.

45. Van Uum SH, Sauve B, Fraser LA, et al. Elevated content of cortisol in hair of patients with severe chronic pain: A novel biomarker for stress. Stress. 2008;11(6):483-488.

46. Thomson S, Koren G, Fraser LA, et al. Hair analysis provides a historical record of cortisol levels in Cushing's syndrome. Exp Clin Endocrinol Diabetes. 2010;118(2):133-138.

47. World Medical Association Declaration of Helsinki. Recommendations guiding physicians in biomedical research involving human subjects. JAMA. 1997;277(11):925-926.

48. American Psychiatric Association. Diagnostic and Statistical Manual of Mental Disorders 4th edition (DSM-IV). Washington DC; American Psychiatric Association; 1994.

49. First MB, Spitzer RL, Gibbon M. Structured Clinical Interview for DSM-IV Diagnoses (SCID): Clinician and Research Versions. New York, NY: Biometrics Research Department, Columbia University; 1996.

50. Radloff LS. The CES-D scale, a self-report depression scale for research in the general population. J Appl Psychol Measurement. 1977; 1:385-401.

51. Beekman AT, Deeg DJ, Van Limbeek J, et al. Criterion validity of the Center for Epidemiologic Studies Depression scale (CES-D): Results from a community-based sample of older subjects in The Netherlands. Psychol Med. 1997;27(1):231-235.

52. Cohen S, Williamson G. Perceived stress in a probability sample of the United States. In: Spacapan S, Oskamp S, editors. The Social Psychology of Health. Thousand Oaks, CA: Sage Publications, Inc.; 1988.

53. Kalra S, Einarson A, Karaskov T, et al. The relationship between stress and hair cortisol in healthy pregnant women. Clin Invest Med. 2007;30(2):E103-E107.

54. Thomson S, Koren G, Fraser L, et al. Hair analysis provides a historical record of cortisol levels in Cushing's syndrome. 2010; 118(2):133-138.

55. Scott KM, Wells JE, Angermeyer M, et al. Gender and the relationship between marital status and first onset of mood, anxiety and substance use disorders. Psychol Med. 2009 Nov 26. [Epub ahead of print].

56. Blazer D. The epidemiology of depression in late life. J Geriatr Psychiatry. 1989;22(1):35-52.

57. Otte C, Marmar CR, Pipkin SS, et al. Depression and 24-hour urinary cortisol in medical outpatients with coronary heart disease: The Heart and Soul Study. Biol Psychiatry. 2004;56(4):241-247.

58. Bhattacharyya MR, Molloy GJ, Steptoe A. Depression is associated with flatter cortisol rhythms in patients with coronary artery disease. J Psychosom Res. 2008;65(2):107-113.

59. Whooley MA, de Jonge P, Vittinghoff E, et al. Depressive symptoms, health behaviors, and risk of cardiovascular events in patients with coronary heart disease. JAMA. 2008;300(20):2379-2388. 
60. Nijm J, Kristenson M, Olsson AG, et al. Impaired cortisol response to acute stressors in patients with coronary disease. Implications for inflammatory activity. J Intern Med. 2007;262(3):375-384.

61. Colao A, Pivonello R, Spiezia S, et al. Persistence of increased cardiovascular risk in patients with Cushing's disease after five years of successful cure. J Clin Endocrinol Metab. 1999;84(8):2664-2672.

62. Girod JP, Brotman DJ. Does altered glucocorticoid homeostasis increase cardiovascular risk? Cardiovasc Res. 2004;64(2):217-226.
63. Kallen VL, Tulen JH, Utens EM, et al. Associations between HPA axis functioning and level of anxiety in children and adolescents with an anxiety disorder. Depress Anxiety. 2008;25(2):131-141.

64. Mookhoek EJ, Sterrenburg-vdNieuwegiessen IM. Screening for somatic disease in elderly psychiatric patients. Gen Hosp Psychiatry. 1998;20(2):102-107.

\section{Publish your work in this journal}

Neuropsychiatric Disease and Treatment is an international, peerreviewed journal of clinical therapeutics and pharmacology focusing on concise rapid reporting of clinical or pre-clinical studies on a range of neuropsychiatric and neurological disorders. This journal is indexed on PubMed Central, the 'PsycINFO' database and CAS, and is the official journal of The International Neuropsychiatric Association (INA). The manuscript management system is completely online and includes a very quick and fair peer-review system, which is all easy to use. Visit http://www.dovepress.com/testimonials.php to read real quotes from published authors.

Submit your manuscript here: http://www.dovepress.com/neuropsychiatric-disease-and-treatment-journal 